\title{
Microwave-Promoted Copper-free Sonogashira-Hagihara Couplings of Aryl Imidazolylsulfonates in water
}

\author{
José F. Cívicos, ${ }^{\mathrm{a}}$ Diego A. Alonso, ${ }^{\mathrm{a} *}$ and Carmen Nájera ${ }^{\mathrm{a}} *$ \\ a Departamento de Química Orgánica and Instituto de Síntesis Orgánica (ISO), Facultad de Ciencias, Universidad de \\ Alicante, Apartado 99, 03080, Alicante, Spain \\ Fax:+34965903549, E-mail: diego.alonso@ua.es, cnajera@ua.es
}

Received: ((will be filled in by the editorial staff))

Supporting information for this article is available on the WWW under http://dx.doi.org/10.1002/adsc.201\#\#\#\#\#\#.((Please delete if not appropriate))

\begin{tabular}{llll} 
Abstract. Aryl imidazol-1-ylsulfonates have been efficiently & hexadecyltrimethylammonium bromide (CTAB) as \\
cross-coupled with aryl-, alkyl-, and silyl acetylenes in neat & additive, and triethylamine (TEA) as base, a wide array of \\
water under copper-free conditions at $110^{\circ} \mathrm{C}$ assisted by & disubstituted alkynes has been prepared in good to high \\
microwave irradiation. Using 0.5 mol\% of an oxime & yields in only 30 minutes. \\
palladacycle as precatalyst, 2-dicyclohexylphosphino-2',6'- & Keywords: Cross-coupling; Sonogashira-Hagihara \\
dimethoxybiphenyl (SPhos, 2 mol\%) as ligand, & Reaction; Microwave Chemistry; Palladacycles; Water. \\
\hline
\end{tabular}

\section{Introduction}

The palladium-catalyzed Sonogashira-Hagihara reaction is one of the most important and widely used methods for preparing aryl- and alkylacetylenes as well as conjugated enynes, ${ }^{[1]}$ which are precursors for natural products, pharmaceuticals, and optical and electronic materials. ${ }^{[1,2]}$ Although aryl- and alkenyl halides are most commonly employed as the electrophilic partner in the Sonogashira reaction, considerable efforts have recently been directed to search for alternative electrophiles. O-Based electrophiles are particularly attractive partners in cross-coupling reactions due to their high stability and the ubiquitous presence of the hydroxylated compounds both in nature and in synthetic systems. Hydroxyarene derivatives offer a valuable alternative given that phenols are typically inexpensive and readily available materials. ${ }^{[3,4]}$ Although triflates have shown high performance as electrophiles in the Pdcatalyzed Sonogashira reaction, their limited stability has focused recent studies on the development of less common but still stable phenol-based electrophiles. ${ }^{[5]}$ Among them, good results have been reported for the palladium-catalyzed coupling of terminal alkynes with aryl mesylates, ${ }^{[6]}$ tosylates, ${ }^{[6,7]}$ phosphonium salts, ${ }^{[8]}$ and imidazolylsulfonates. ${ }^{[9]}$ However, these couplings have all been performed using high catalyst loadings (2-10 $\mathrm{mol} \% \mathrm{Pd})$, usually in the presence of a copper salt as cocatalyst, and employing organic solvents as reaction medium (Scheme 1). Very recently, we have disclosed a phosphane-free oximepalladacycle ${ }^{[10,11]}$-catalyzed Suzuki cross-coupling reaction of aryl imidazol-1-ylsulfonates ${ }^{[12]}$ with arylboronic acids and potassium aryl trifluoroborates in aqueous methanol, reaction which can be performed using conventional or microwave heating, under conditions with low catalyst loading (1 $\mathrm{mol} \%$ Pd). ${ }^{[13]}$ This coupling can be also performed in neat water by using the cationic surfactant ${ }^{[14]}$ hexadecyltrimethyl ammonium bromide (CTAB) as additive, which has allowed to cross- couple aryl imidazol-1-ylsulfonates with potassium aryl- and alkenyltrifluoroborates under microwave heating (40 $\mathrm{W}, 110^{\circ} \mathrm{C}$ ) using $0.5 \mathrm{~mol} \%$ of oxime palladacycle 1a. ${ }^{[15]}$

To date, no examples have been reported for transition-metal catalyzed Sonogashira crosscoupling of phenol derivatives in neat water (Scheme 1). ${ }^{[16]}$ In this communication, we present the first Sonogashira coupling of aryl imidazolylsulfonates performed in neat water using oxime palladacycle 1a as precatalyst under microwave irradiation (Scheme $1)$.

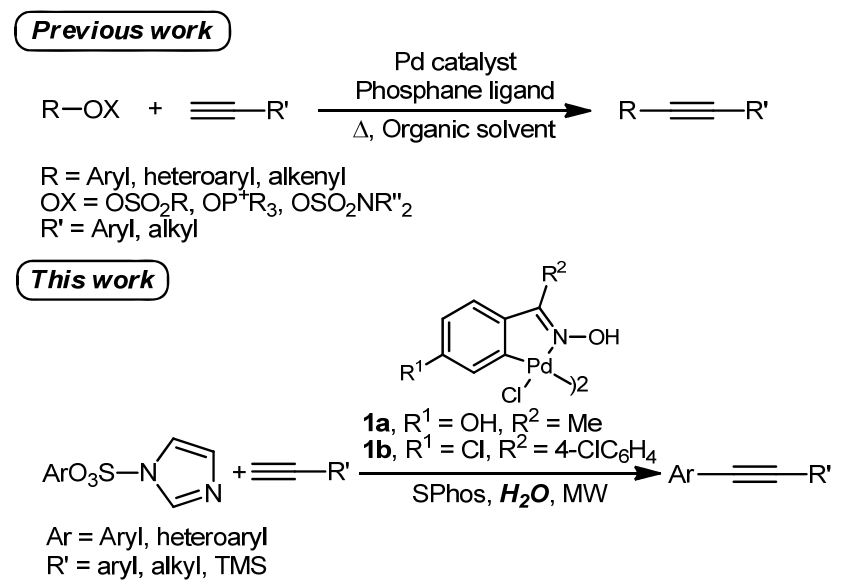


Scheme 1. Sonogashira Coupling of Phenol-derived Electrophiles.

\section{Results and Discussion}

Initially, we investigated the microwavepromoted Sonogashira coupling of naphthalen-1-yl $1 \mathrm{H}$-imidazole-1-sulfonate (2aa, 1equiv) with phenyl acetylene (1.5 equiv) in water in the presence of CTAB (3a), which was the best surfactant in the Suzuki reaction, ${ }^{[13]}$ and TEA (2 equiv) as base (Scheme 2). With an initial microwave irradiation of $40 \mathrm{~W}$, the reaction temperature was maintained at 110 ${ }^{\circ} \mathrm{C}$ for $30 \mathrm{~min}$. As catalyst, oxime palladacycle 1a (1 $\mathrm{mol} \% \mathrm{Pd}$ ) was selected to perform the initial screening due to the high activity of this complex as precatalyst in different cross-coupling and Heck type reactions in aqueous medium. ${ }^{[11,13,14]}$ Unfortunately, under these conditions, the alkynylation did not take place and starting materials were mostly recovered (Scheme 2). Since we have previously demonstrated the improvement of the activity of oxime palladacycles using phosphanes in the Suzuki arylation $^{[17 a]}$ and alkenylation ${ }^{[17 b]}$ reaction of the challenging deactivated aryl chlorides, we assembled a small catalyst library prepared in situ by mixing 1a (1 mol\% Pd) and different electron-rich and sterically demanding ligands ( $2 \mathrm{~mol} \%$ ). As depicted in Scheme 2 , the most active catalytic system was obtained when using Buchwald's ligands $\mathbf{9}$ and 10, especially the tertiary electron-rich and sterically hindered SPhos ligand 10, which led to an excellent 96\% isolated yield for 4a. Other mono- and bidentate phosphanederived ligands such as $\mathbf{5 - 1 2}$ as well as the sterically hindered phosphate $\mathbf{1 3}$ and the imidazolinium NHC ligand $\mathbf{1 4}$ always led to lower yields in the process (Scheme 2).

Having identified SPhos as the optimal ligand for the copper-free Sonogashira reaction in water, further reaction conditions optimization was carried out in order to improve the efficiency of the catalytic system (Table 1). ${ }^{[18]}$

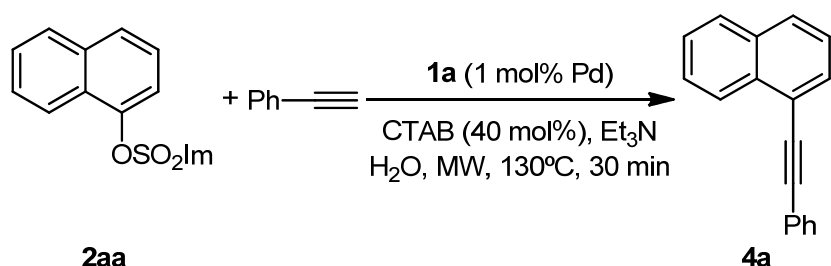

2aa

$4 a$

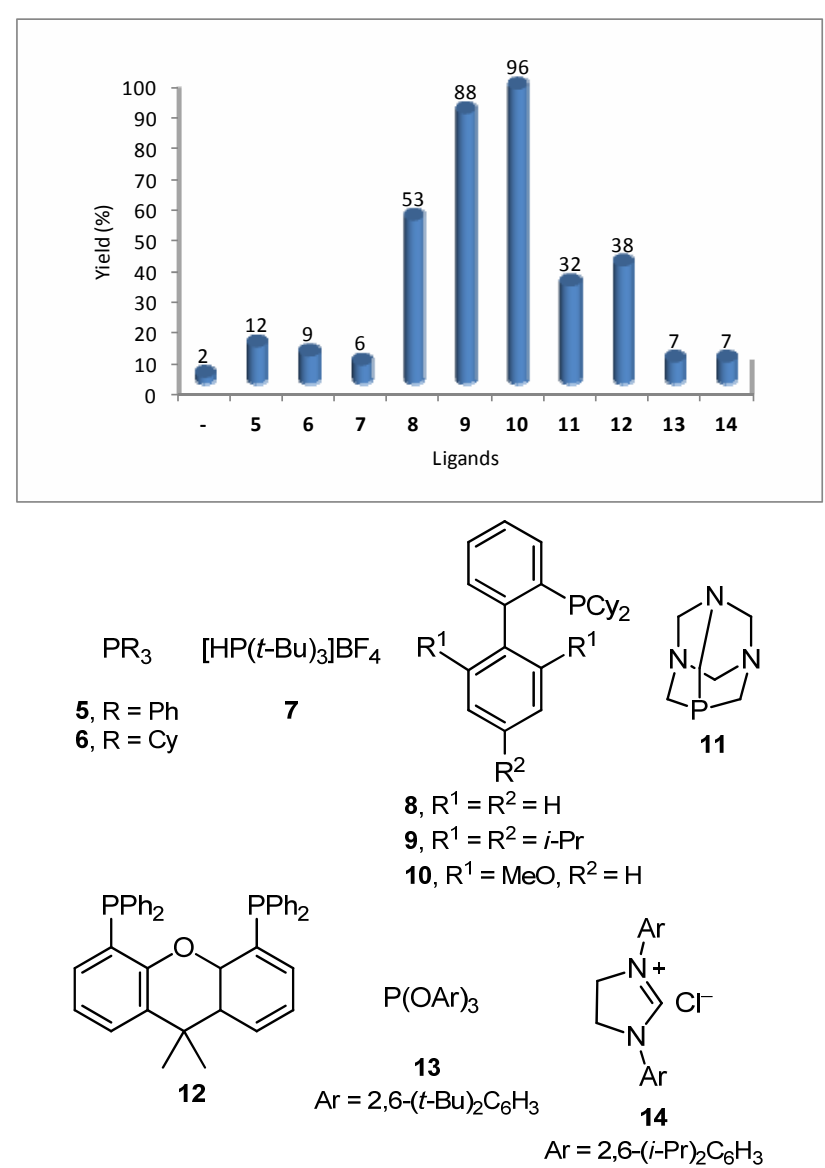

Scheme 2. Sonogashira Coupling in water. Ligands Study.

Table 1. Sonogashira alkynylation of 2 in water. Reaction conditions study.

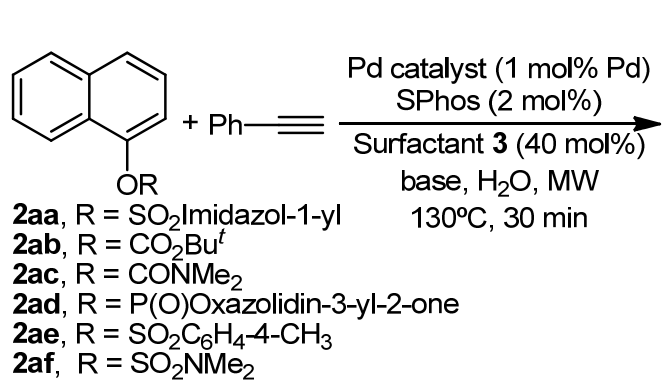

\begin{tabular}{llllll}
\hline Entry & $\mathbf{2}$ & Surfactant $^{\text {a) }}$ & Pd cat. & Base & $\begin{array}{l}\text { Yield } \\
(\%)^{\text {b) }}\end{array}$ \\
\hline 1 & 2aa & CTAB (3a) & 1a & TEA & $\begin{array}{l}96 \\
(48)^{\text {c) }}\end{array}$ \\
2 & 2aa & CTAB (3a) & 1b & TEA & 58
\end{tabular}




\begin{tabular}{|c|c|c|c|c|}
\hline 3 & 2aa & CTAB (3a) & $\mathrm{Pd}(\mathrm{OAc})_{2}$ & TEA \\
\hline 4 & 2aa & CTAB (3a) & $\mathrm{Pd}_{2}(\mathrm{dba})_{3}$ & TEA \\
\hline 5 & 2aa & СТАВ (3a) & 1a & Pyrrolidine \\
\hline 6 & 2aa & СТAB (3a) & $1 \mathbf{a}$ & $\mathrm{K}_{2} \mathrm{CO}_{3}$ \\
\hline 7 & 2aa & CTAB (3a) & 1a & $\mathrm{KOH}$ \\
\hline 8 & 2aa & CTAB (3a) & 1a & $\mathrm{CsOH}$ \\
\hline 9 & 2aa & CTAB (3a) & 1a & $\mathrm{K}_{3} \mathrm{PO}_{4}$ \\
\hline 10 & 2aa & TBAOH (3b) & 1a & TEA \\
\hline 11 & 2aa & SDS (3c) & 1a & TEA \\
\hline 12 & 2aa & $\begin{array}{l}\text { Maxemul6112 } \\
\text { (3d) }\end{array}$ & 1a & TEA \\
\hline 13 & 2aa & PTS (3e) & 1a & TEA \\
\hline 14 & 2aa & SPAN80 (3f) & 1a & TEA \\
\hline 15 & 2aa & $\begin{array}{l}\text { ZONYL } 9361 \\
\text { (3g) }\end{array}$ & 1a & TEA \\
\hline 16 & 2aa & $\begin{array}{l}\text { ZONYL FSN } \\
\text { (3h) }\end{array}$ & 1a & TEA \\
\hline 17 & 2ab & CTAB (3a) & 1a & TEA \\
\hline 18 & 2ac & CTAB (3a) & 1a & TEA \\
\hline 19 & 2ad & СТАВ (3a) & 1a & TEA \\
\hline 20 & 2ae & CTAB (3a) & 1a & TEA \\
\hline 21 & 2af & CTAB (3a) & $1 \mathbf{a}$ & TEA \\
\hline
\end{tabular}

CTAB: hexadecyltrimethyl ammonium bromide; TBAOH: tetrabutylammonium hydroxide; SDS: sodium dodecyl sulphate; PTS: polyoxyethanyl- $\alpha$-tocopheryl sebacate; for the rest of surfactant acronyms, see SI; b) Isolated yield after flash chromatography. ${ }^{\text {c) }}$ Isolated yield when the reaction was performed under conventional thermal conditions $\left(130^{\circ} \mathrm{C}, 24 \mathrm{~h}\right)$.

Initially, the efficiency of the microwave irradiation was demonstrated since only a $48 \%$ yield was obtained for $\mathbf{4 a}$ when the reaction was performed under conventional thermal conditions $\left(130^{\circ} \mathrm{C}, 24 \mathrm{~h}\right.$, Table 1, entry 1). Regarding the catalyst, a 58\% yield of 1-(phenylethynyl)naphthalene was obtained under the optimized reaction conditions when oxime palladacycle $\mathbf{1 b}(1 \mathrm{~mol} \% \mathrm{Pd})$ was employed as catalyst (Table 1 , entry 2 ). This result confirmed the facility of palladacycle 1a in cross-coupling reactions in aqueous medium. Other $\mathrm{Pd}$ sources such as $\mathrm{Pd}(\mathrm{OAc})_{2}$ and $\mathrm{Pd}_{2}(\mathrm{dba})_{3}$ were also less effective than 1a affording lower yields of $\mathbf{4 a}$ as shown in entries 3 and 4.

With respect to the base (Table 1, entries 5-9), good isolated yields were obtained with other organic (pyrrolidine, 89\%) and inorganic bases $\left(\mathrm{K}_{2} \mathrm{CO}_{3}\right.$ and $\mathrm{K}_{3} \mathrm{PO}_{4}, 75$ and $78 \%$, respectively), though these experiments did not improve the ability of TEA in this process.

The effect of the surfactant on the activity of the catalytic system was also studied (Table 1, entries 1016). Regardless of the ionic character of the additive, lower yields were observed for the alkynylation reaction, with the exception of the anionic phosphate ester-derived surfactant MAXEMUL 6112, which afforded $4 \mathbf{a}$ in a $91 \%$ isolated yield (Table 1, entry 12).
Finally, we also tested the reactivity of the electrophiles 2ab-2af in the process under the optimized reaction conditions. As depicted in Table 1 (entries 17-21), none of these derivatives showed any reactivity and only starting material was recovered from the crude reaction mixture.

To test the effectiveness of the catalytic system in the Pd-catalyzed Sonogashira coupling in water, a range of terminal alkynes were examined in the reaction with imidazol-1-ylsulfonate 2aa under the optimized reaction conditions (Table 2). Thus, naphthalen-1-yl $1 H$-imidazole-1-sulfonate (2aa) was coupled with 4-tolyl- and 4-methoxyphenylacetylene in excellent 96 and $87 \%$ yield, respectively (Table 2, entries 2 and 3). Lower yields were achieved in the coupling with the electron-poor 4(trifluoromethyl)phenyl-, and 2-pyridyl acetylene (Table 2, entries 4 and 5), results which were also observed for alkyl substituted acetylenes such as cyclohexyl acetylene (63\%, entry 6) and 1-butyne (40\%, entry 7). In the case of using trimethylsilylacetylene as nucleophile, a double arylation process was observed affording 1,2di(naphthalen-1-yl)ethyne (15) as major product in a $45 \%$ isolated yield (Table 2, entry 8 ). Unfortunately, this yield could not be improved by using two equivalents of electrophile, conditions which afforded 15 in a poor $15 \%$ yield. When 2aa was allowed to react with propiolic acid, the double coupling process was also observed affording 15 in a $37 \%$ yield (Table 2 , entry 9). However, the alkynylation of 2aa with 2methylbut-3-yn-2-ol, led to the monoarylated compound $\mathbf{4 j}$ in a $38 \%$ yield (Table 2 , entry 10 ).

Table 2. Sonogashira Cross-coupling Reaction. Nucleophile Scope.

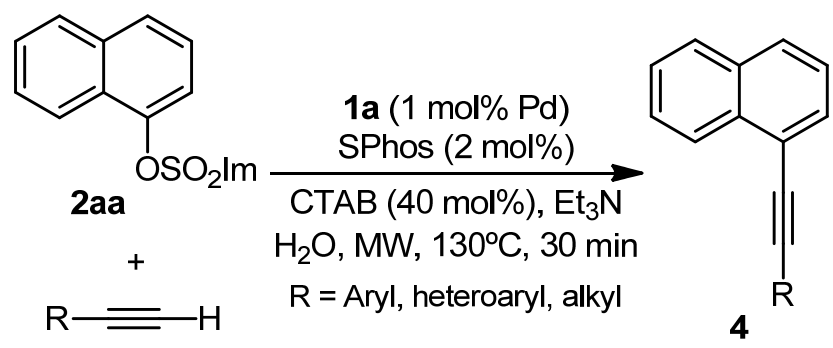

\begin{tabular}{llll}
\hline Entry & $\mathrm{R}$ & No. & Yield (\%) \\
\hline 1 & $\mathrm{Ph}$ & $\mathbf{4 a}$ & 96 \\
2 & $4-\mathrm{MeC}_{6} \mathrm{H}_{4}$ & $\mathbf{4 b}$ & 96 \\
3 & $4-\mathrm{MeOC}_{6} \mathrm{H}_{4}$ & $\mathbf{4 c}$ & 87 \\
4 & $4-\mathrm{CF}_{3} \mathrm{C}_{6} \mathrm{H}_{4}$ & $\mathbf{4 d}$ & 59 \\
5 & $2-p y r i d y l$ & $\mathbf{4 e}$ & 52 \\
6 & $\mathrm{Cyclohexyl}_{7}$ & $\mathbf{4 f}$ & 63 \\
7 & $\mathrm{C}_{3} \mathrm{H}_{7}$ & $\mathbf{4 g}$ & 40 \\
8 & $\mathrm{TMS}_{9}$ & $\mathbf{1 5}$ & $45^{\mathrm{b}), \mathrm{c})}$ \\
10 & $\mathrm{CO}_{2} \mathrm{H}$ & $\mathbf{1 5}$ & $37^{\mathrm{b}), \mathrm{d})}$ \\
\hline
\end{tabular}


a) Isolated yield after flash chromatography. b) Isolated yield for 1,2-di(naphthalen-1-yl)ethyne (15). ${ }^{\text {c) }}$ A 7\% yield (GC) of trimethyl(naphthalen-1-ylethynyl)silane (4h) was also detected in the crude reaction mixture. ${ }^{\text {d) }}$ A 7\% yield
(GC) of 3-(naphthalen-1-yl)propiolic acid (4i) was also detected in the crude reaction mixture.

Table 3. Sonogashira Cross-coupling Reaction. Substrate Scope.
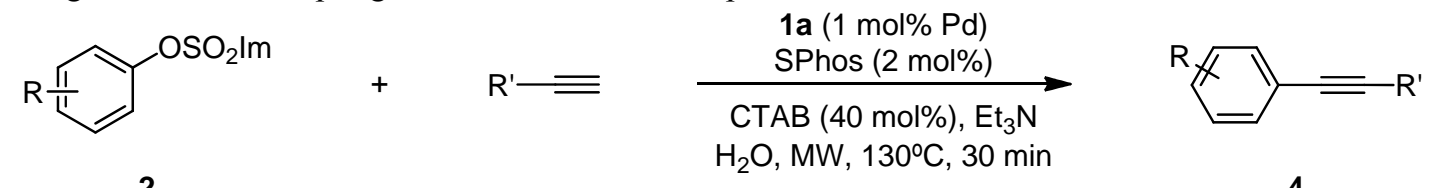

2

$\mathrm{H}_{2} \mathrm{O}, \mathrm{MW}, 130^{\circ} \mathrm{C}, 30 \mathrm{~min}$

\begin{tabular}{|c|c|c|c|c|c|c|}
\hline Entry & $\mathrm{ArOSO}_{2} \mathrm{Im}$ & No. & $\mathrm{R}^{\prime}=$ & Product & No. & Yield (\%) \\
\hline 1 & & $2 \mathrm{ba}$ & $\mathrm{Ph}=$ & & $4 k$ & 89 \\
\hline 2 & & $2 \mathrm{ca}$ & $\mathrm{Ph}=$ & & 41 & 78 \\
\hline 3 & & 2da & $\mathrm{Ph}=$ & & $4 m$ & 55 \\
\hline 4 & & 2ea & $\mathrm{Ph} \equiv$ & & $4 n$ & $77^{\mathrm{b})}$ \\
\hline 5 & & $2 \mathrm{fa}$ & $\mathrm{Me}-$ & & 40 & 94 \\
\hline 6 & & $2 g a$ & $\mathrm{Ph}=$ & & $4 p$ & 92 \\
\hline 7 & & $2 g a$ & $\mathrm{MeC}$ & & $4 q$ & 87 \\
\hline 8 & & $2 g a$ & $\mathrm{HO}>$ & & $4 r$ & $92^{\text {c) }}$ \\
\hline 9 & & 2ha & $\mathrm{Me}-$ & & $4 s$ & 95 \\
\hline 10 & & 2ha & $\mathrm{HO}>$ & & $4 t$ & $41^{d)}$ \\
\hline 11 & & $2 i a$ & $\mathrm{Ph}=$ & & $4 u$ & 45 \\
\hline
\end{tabular}

a) Isolated yield after flash chromatography. ${ }^{\text {b) }}$ A 7\% yield (GC) of 1,4-bis(phenylethynyl)benzene (16) was also detected in the crude reaction mixture. c) A $6 \%$ yield (GC) of 1,2-di-o-tolylethyne (17) was also detected in the crude reaction mixture. d) A 5\% yield (GC) of 1,2-bis(2,6-dimethylphenyl)ethyne (18) was also detected in the crude reaction mixture.

Regarding the electrophilic component, moderate to high yields $(45-95 \%)$ were obtained in the 
microwave-assisted 1a/S-Phos-catalyzed crosscoupling of different terminal acetylenes with neutral, electron-rich, and electron-poor phenylimidazol-1ylsulfonates (Table 3). Thus, phenyl $1 H$-imidazole-1sulfonate (2ba) and the electron-rich 4methoxyphenyl $1 H$-imidazole-1-sulfonate (2ca) and 3,5-dimethylphenyl $1 \mathrm{H}$-imidazole-1-sulfonate (2da) reacted with phenylacetylene to afford compounds $\mathbf{4 k}$, 4l, and $\mathbf{4 m}$ in a 89,78 , and $55 \%$ yield, respectively (Table 3, entries 1-3). High yields were also observed for the coupling of the activated electrophiles 2ea and 2fa with phenylacetylene and 4-tolylacetylene, respectively (Table 3, entries 4 and 5). The process was also effective for the coupling of 2-aryl- and 2alkylacetylenes with deactivated and sterically hindered electrophiles such as $O$-tolyl $1 H$-imidazole1-sulfonate (2ga) and 2,6-dimethylphenyl $1 \mathrm{H}$ imidazole-1-sulfonate (2ha), reactions which afforded the corresponding cross-coupled products in yields ranging from 41 to $95 \%$ (Table 3, entries 6-10). Finally, the heterocyclic pyridin-2-yl $1 H$-imidazole1-sulfonate (2ia) led to compound $\mathbf{4 u}$ in a modest $45 \%$ yield after reaction with phenylacetylene (Table 3 , entry 11$)$.

\section{Conclusion}

We have disclosed a copper-free oxime palladacyclecatalyzed Sonogashira cross-coupling reaction of electron-rich, electron-poor, and sterically hindered aryl imidazol-1-ylsulfonates with aryl- and alkylsubstituted terminal alkynes using water as solvent under microwave irradiation. This reaction is carried out in the presence of SPhos as ligand (2 mol\%), hexadecyltrimethylammonium bromide as additive, and using only $1 \mathrm{~mol} \% \mathrm{Pd}$ of bench stable oxime palladacycle 1a as precatalyst. Further studies to demonstrate the ability of imidazolylsulfonates as electrophiles in cross-coupling reactions in water are underway in the group.

\section{Experimental Section}

\section{Typical Procedure for the Sonogashira Coupling in water under MW Irradiation Conditions}

A $10 \mathrm{~mL}$ MW vessel was charged with 2cyanophenyl $1 \mathrm{H}$-imidazole-1-sulfonate $(0.050 \mathrm{~g}, 0.2$ mmol, 1 equiv), $p$-tolylacetylene $(0.038 \mathrm{~mL}, 0.3$ $\mathrm{mmol}), \quad \mathrm{Et}_{3} \mathrm{~N} \quad(0.056 \mathrm{ml}, 0.4 \mathrm{mmol})$, hexadecyltrimethylammonium bromide $(0.03 \mathrm{~g}, 40$ mol\%), catalyst 1 a $(0.6 \mathrm{mg}, 1 \mathrm{~mol} \% \mathrm{Pd}), \mathrm{H}_{2} \mathrm{O}(1.7$ $\mathrm{mL})$ and SPhos $(0.0017 \mathrm{~g}, 2 \mathrm{~mol} \%)$. The vessel was sealed with a pressure lock, and the mixture was heated in air at $130{ }^{\circ} \mathrm{C}$ for 30 min with the aid of an initial 40W MW irradiation in a CEM Discover MW reactor. After cooling to room temperature, the reaction mixture was extracted with EtOAc $(3 \times 10$ $\mathrm{mL})$, and the organic layers were washed with $\mathrm{H}_{2} \mathrm{O}(3$ $\times 10 \mathrm{~mL}$ ), dried over $\mathrm{MgSO}_{4}$, and concentrated under reduced pressure. The crude residue was purified by flash chromatography (hexane) to obtain $0.040 \mathrm{~g}$ of compound 40 (94\% yield).

\section{Acknowledgements}

Financial support from the MICINN (Projects CTQ200762771/BQU, CTQ2010-20387, and Consolider INGENIO 2010 CSD2007-00006), FEDER, from the Generalitat Valenciana (Project PROMETEO/2009/038), and the University of Alicante is acknowledged.

\section{References}

[1] For reviews, see: a) K. Sonogashira, J. Organomet. Chem. 2002, 653, 46; b) E.-i. Negishi, L. Anastasia, Chem. Rev. 2003, 103, 1979; c) R. Chinchilla, C. Nájera, Chem. Rev. 2007, 107, 874; d) H. Doucet, J.-C. Hierso, Angew. Chem., Int. Ed. 2007, 46, 834; e) H. Plenio, Angew. Chem., Int. Ed. 2008, 47, 6954; f) R. Chinchilla, C. Nájera, Chem. Soc. Rev. 2011, 40, 5084; g) N. M. Jenny, M. Mayor, T. R. Eaton, Eur. J. Org. Chem. 2011, 4965.

[2] a) N. Weibel, S. Grunder, M. Mayor, Org. Biomol. Chem. 2007, 5, 2343: b) K. C. Nicolaou, P. G. Bulger, D. Sarlah, Angew. Chem. Int. Ed. 2005, 44, 4442; c) M. Kivala, F. Diederich, Pure Appl. Chem. 2008, 80, 411.

[3] The Chemistry of Phenols (Ed.: Z. Rappoport), John Wiley \& Sons Ltd., Chichester, 2003.

[4] D. A. Alonso, C. Nájera, I. Pastor, M. Yus, Chem. Eur. J. 2010, 16, 5274.

[5] For recent reviews on the use of new C-O electrophiles in cross-coupling reactions, see: a) D.-G. Yu, B.-J. Li, Z.-J. Shi, Acc. Chem. Res. 2010, 43, 1486. b) B.-J. Li, D.-G. Yu, C.-L. Sun, Z.-J. Shi, Chem. Eur. J. 2011, 17, 1728.

[6] For a recent study, see: P. Y. Choy, W. K. Chow, C. M. So, C. P. Lau, F. Y. Kwong, Chem. Eur. J. 2010, 16, 9982. [7] For recent studies, see: a) D. Gelman, S. L. Buchwald, Angew. Chem. Int. Ed. Engl. 2003, 42, 5993; b) H. Nakatsuji, K. Ueno, T. Misaki, Y. Tanabe, Org. Lett. 2008, 10, 2131; c) Y. Luo, J. Wu, Tetrahedron 2009, 65, 6810; d) O. R'kyek, N. Halland, A. Lindenschmidt, J. Alonso, P. Lindemann, M. Urmann, M. Nazaré, Chem. Eur. J. 2010, 16, 9986.

[8] For recent studies, see: a) F.-A. Kang, J. C. Lanter, C. Cai, Z. Sui, W. V. Murray, Chem. Commun. 2010, 46, 1347; b) C. Shi, C. C. Aldrich, Org. Lett. 2010, 12, 2286.

[9] S. J. Shirbin, B. A. Boughton, S. C. Zammit, S. D. Zannatta, S. M. Marcuccio, C. A. Hutton, S. J. Williams, Tetrahedron Lett. 2010, 51, 2971.

[10] Palladacycles: Synthesis, Characterization and Applications, (Eds.: J. Dupont, M. Pfeffer), Wiley-VCH, Weinheim, 2008. 
[11] For reviews on the use of oxime-palladacycles as precatalysts in cross-coupling reactions, see: a) D. A. Alonso, L. Botella, C. Nájera, M. C. Pacheco, Synthesis 2004, 1713; b) E. Alacid, D. A. Alonso, L. Botella, C. Nájera, M. C. Pacheco, Chem. Rec. 2006, 6, 117; c) D. A. Alonso, C. Nájera, Chem. Soc. Rev. 2010, 39, 2891.

[12] For the use of aryl imidazolylsulfonates in other crosscoupling reactions, see: a) Y. Luo, J. Wu, Organometallics 2009, 28, 6823. b) S. J. Shirbin, B. A. Boughhton, S. C. Zammit, S. D. Zanatta, S. M. Marcuccio, C. A. Hutton, S. J. Williams, Tetrahedron Lett. 2010, 51, 2971. c) L. Ackermann, S. Barfüesser, J. Pospech, Org. Lett. 2010, 12, 724.

[13] a) J. F. Cívicos, M. Gholinejad, D. A. Alonso, C. Nájera, Chem. Lett. 2011, 40, 907. b) J. F. Cívicos, D. A. Alonso, C. Nájera, Eur. J. Org. Chem. 2012, 3670-3676.
[14] For a recent review about surfactant-enable crosscoupling reactions in water, see: B. H. Lipshutz, S. Ghorai, Aldrichimica Acta, 2012, 45, 3.

[15] J. F. Cívicos, D. A. Alonso, C. Nájera, Adv. Synth. Catal. 2012, 354, 2771-2776.

[16] For a recent review about cross-coupling and Heck reactions using water as solvent, see: D. A. Alonso, C. Nájera in Science of Synthesis. Water in Organic Synthesis (Ed. S. Kobayashi), George Thieme Verlag KG, Stuttgart, 2012, Vol. 2011/7, p 535.

[17] a) J. F. Cívicos, D. A. Alonso, C. Nájera, Synlett 2009, 3011. b) J. F. Cívicos, D. A. Alonso, C. Nájera, Adv. Synth. Catal. 2011, 353, 1683.

[18] For the full reaction optimization study, see the SI. 


\section{FULL PAPER}

Microwave-Promoted Copper-free SonogashiraHagihara Couplings of Aryl Imidazolylsulfonates in water

Adv. Synth. Catal. Year, Volume, Page - Page

José F. Cívicos, Diego A. Alonso, * and Carmen Nájera*

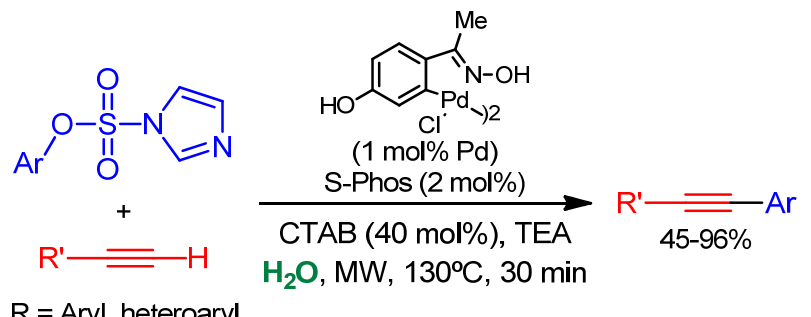

$\mathrm{R}^{\prime}=$ Aryl, alkyl, TMS, $\mathrm{CO}_{2} \mathrm{H}$ 